\title{
Sinus membrane elevation and implant placement
}

\author{
Young-Kyun Kim, DDS, PhD ${ }^{1,2,3}$, Jeong-Kui Ku, DDS, PhD, FIBCOMS ${ }^{4,5}$ \\ ${ }^{1}$ Editor-in-Chief of J Korean Assoc Oral Maxillofac Surg, ${ }^{2}$ Department of Oral and Maxillofacial Surgery, \\ Section of Dentistry, Seoul National University Bundang Hospital, Seongnam, \\ ${ }^{3}$ Department of Dentistry \& Dental Research Institute, School of Dentistry, Seoul National University, Seoul, \\ ${ }^{4}$ Section Editor of J Korean Assoc Oral Maxillofac Surg, ${ }^{5}$ Department of Oral and Maxillofacial Surgery, \\ Section of Dentistry, Armed Forces Capital Hospital, Armed Forces Medical Command, Seongnam, Korea
}

\begin{abstract}
J Korean Assoc Oral Maxillofac Surg 2020;46:292-298)
Sinus Schneiderian membrane elevation surgery is widely performed for dental implant placement in the maxillary posterior region. With regard to sinus elevation surgery, various complications can occur and lead to implant failure. For successful implants in the maxillary posterior region, the clinician must be well acquainted with sinus anatomy and pathology, a variety of bone graft materials, the principles of sinus elevation surgery, and prevention and management of complications.
\end{abstract}

Key words: Sinus membrane elevation, Complication, Success

[paper submitted 2020. 7. 27 / accepted 2020. 7. 27]

\section{Introduction}

Dental implants in the maxillary posterior region are known to exhibit poor clinical outcomes due to lack of residual bone height and poor bone quality. Various surgical techniques have been developed to compensate for bone quality and quantity of the maxillary posterior region. Regarding insufficient residual bone height, sinus Schneiderian membrane elevation should be performed to prevent maxillary sinus invasion of dental implants. Although bone grafting surgery is commonly accompanied by this procedure, sinus membrane elevation is performed without bone grafting. These surgical techniques have been introduced using the following terms: sinus graft, sinus bone graft, sinus lift graft, sinus augmentation, maxillary sinus augmentation, maxillary

\footnotetext{
Young-Kyun Kim

Department of Oral and Maxillofacial Surgery, Section of Dentistry, Seoul National University Bundang Hospital, 82 Gumi-ro 173beon-gil, Bundanggu, Seongnam 13620, Korea

TEL: +82-31-787-7541 FAX: +82-31-787-4068

E-mail:kyk0505@snubh.org

ORCID: https://orcid.org/0000-0002-7268-3870

(2) This is an open-access article distributed under the terms of the Creative Commons Attribution Non-Commercial License (http://creativecommons.org/ licenses/by-nc/4.0/), which permits unrestricted non-commercial use, distribution, and reproduction in any medium, provided the original work is properly cited.

Copyright $(\mathcal{C} 2020$ The Korean Association of Oral and Maxillofacial Surgeons. All rights reserved.
}

sinus floor bone grafting, sinus lift (elevation), sinus membrane elevation, sinus floor elevation, sinus filling (packing), and sinus repair ${ }^{1}$. Concerning sinus elevation surgery, many studies have been classified candidates into relative and absolute contraindications, but the decision of surgical technique is mainly dependent on the preference and experience of the clinician ${ }^{2}$.(Table 1)

\section{Types of Sinus Membrane Elevation Surgery}

Sinus membrane elevation surgery is classified into crestal (internal sinus lift, socket lift) and lateral (lateral sinus lift) approaches. Generally, the type of approach is selected based on residual bone height. The crestal approach is safe in cases of residual bone height greater than $5 \mathrm{~mm}$, and bone height of 3-4 $\mathrm{mm}$ can be obtained. The lateral approach is recommended when residual bone height is $5 \mathrm{~mm}$ or less ${ }^{3}$.

\section{Crestal approach}

Since the 1990s, sinus membrane elevation has been performed using an osteotome technique such as osteotomy sinus floor elevation (OSFE), bone added OSFE (BAOSFE), future site development (FSD), and trabecular compaction ${ }^{4,5}$. 
Table 1. Classification of contraindications

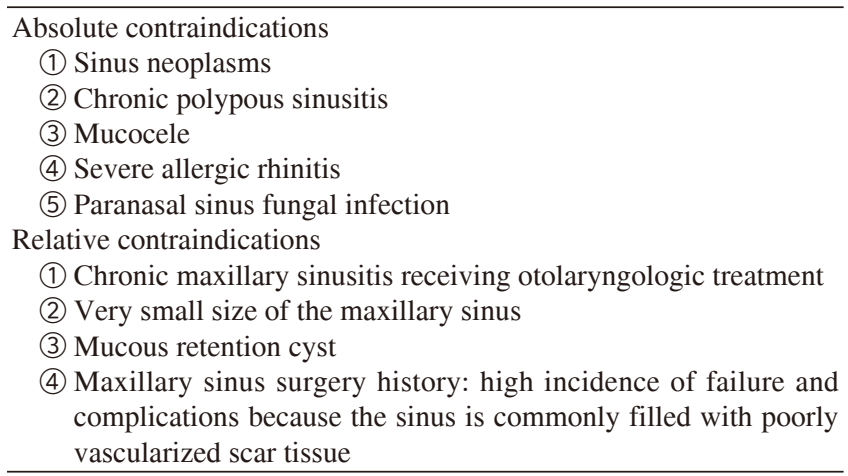

Young-Kyun Kim et al: Sinus membrane elevation and implant placement. J Korean Assoc Oral Maxillofac Surg 2020

Recently, however, these techniques have not been widely used due to their high risk of sinus membrane perforation and complications. In addition, many devices have been developed that can safely contribute to the crestal approach. To prevent the risk of complications such as sinus perforation, head trauma, and vertigo, devices such as balloons, hydraulic pressure, special reamers, and piezoelectric drills are used ${ }^{5-9}$. With regard to the crestal approach, many implants are simultaneously placed with the approach, and bone grafting is performed based on the amount of elevation required and the preference of the clinician.

\section{Lateral approach}

The lateral approach is mainly performed when residual bone height is $<5 \mathrm{~mm}$ or pathologic conditions are observed in the sinus. After forming a lateral window with various instruments, the sinus membrane can be elevated. Even though special surgical techniques with various instruments and drills have been developed to minimize risk of sinus membrane perforation, surgeon skill and experience is critical to prevent complications ${ }^{9,10}$.

\section{1) Sinus membrane elevation without bone grafting}

Many studies have reported on the lateral approach without bone grafting. To maintain the space without lowering the membrane after sinus lift, the area is packed with a resorbable membrane, titanium mesh, collagen sponge, platelet-rich plasma (PRP) gel, resorbable polymeric thermos-reversible gel (Poloxamer), reoxidized cellulose, or venous blood ${ }^{11-14}$. Several studies have reported that sinus bone formed an average height of 4.7-9.1 mm. To achieve stable and successful outcomes, the condition of the maxillary sinus should be healthy, and the sinus membrane must not be perforated dur- ing surgery. This technique is recommended in cases of residual bone height $>5 \mathrm{~mm}$, with new bone formation expected to be approximately $3 \mathrm{~mm}^{15,16}$.

2) Bone graft materials for sinus grafting

Autogenous bone graft has the advantage of a shortened healing period. Without autogenous bone, the healing period can be as long as 8 months ${ }^{17,18}$. Use of autogenous endochondral bone (e.g., tibia and iliac bone) has become rare due to complications with donor site ${ }^{19}$. Recently, many clinicians have been harvesting block or particulated autogenous bone at an intraoral site (e.g., mandible, maxilla, and zygoma) and including other bone substitutes to increase the amount of harvested bone $\mathrm{e}^{20-22}$.

Allogeneic, xenogeneic, and alloplastic bone substitute materials are used alone or in combination. To promote new bone formation, bone substitutes can be incorporated with platelet-rich fibrin (PRF), PRP, and recombinant human bone morphogenetic protein-2 (rhBMP-2). Xenogeneic bones are mainly manufactured from bovine, equine, and porcine species. Alloplastic bone substitutes such as hydroxyapatite (HA), calcium sulfate, beta-tricalcium phosphate ( $\beta$-TCP), and bioactive glass have generally been used for sinus bone grafting. In recent years, most alloplastic bone products have been composed independent of any other products or in a specific ratio with $\mathrm{HA}$ and $\beta-\mathrm{TCP}^{23-28}$.

Generally, any bone substitutes can be expected to have a successful outcome with sinus bone grafting if there is no sinus-related pathology, a healthy Schneiderian membrane, proper residual bone height, and no perforation during surgery ${ }^{29-31}$. Some studies have suggested that application of 0.25-1.00 mm of granular bone graft could enhance bone formation because of the intimate contact surface with the recipient bone wall ${ }^{32}$. However, Chackartchi et al. ${ }^{33}$ reported that particle sizes of $1.00-2.00 \mathrm{~mm}$ and $0.25-1.00 \mathrm{~mm}$ exhibited similar results, with smaller-size particles showing greater resorption. Therefore, the authors recommended a mixture of small- and large-size particulated bone graft for large defects.

3) Simultaneous versus delayed implant placement

For primary stability of implants, simultaneous implant placement should be performed on residual bone height $\geq 3$ $\mathrm{mm}$, and delayed implant placement should be considered in areas of 1-2 $\mathrm{mm}$ of residual bone height. When considering these indications, simultaneous and delayed methods have shown similar successful outcomes ${ }^{34}$. 
4) Lateral window formation

It is evident that the smaller is the size of the lateral window; the better is the bone formation. A smaller window has a high risk of sinus membrane perforation due to the narrow operating field. Active new bone formation can be achieved with clear membrane elevation to create an enclosed space with surrounding bone, similar to an extraction socket.

The trapdoor technique has been widely used to form the lateral window by fracturing the window inward and moving it upward with membrane elevation. However, the risk of membrane perforation increases in cases with sinus septum. Some clinicians prefer to reposition the window after membrane elevation with bone graft material ${ }^{35}$. Other clinicians have argued that removal of the window with a diamond bur or reamer is easier and safer for lifting the membrane. After removing the window, a barrier membrane should be used to cover the window defect to prevent soft tissue ingrowth ${ }^{36}$.

\section{An Alternative Technique for Sinus Membrane Elevation}

Maxillary tuberosity implants, short implants, and tilted implants have been introduced to avoid the maxillary sinus during implant therapy ${ }^{37}$. Chiapasco and Zaniboni ${ }^{38}$, however, noted that sinus membrane elevation with bone grafting is better suited for the final prosthesis as it allows the implant to be placed in an ideal position even though it is more invasive and involves higher complication risk.

\section{Healing After Sinus Bone Grafting}

The healing period varies depending on several variables, including residual bone height, sinus cavity width, graft material, age of the patient, smoking history, and complications such as sinus membrane perforation and infection. In general, a healing period of 6-8 months is required between placement of the bone graft material and maturation of new bone ${ }^{39}$. It is clear that the higher is the residual bone from the sinus floor, the shorter is the healing period, the lower is the complication risk, and the higher is the success rate of bone grafting

Table 2. Intraoperative complications

1. Implant fixture sinus displacement

2. Posterior alveolar superior artery bleeding

3. Sinus membrane perforation

4. Implant protrusion into the maxillary sinus

Young-Kyun Kim et al: Sinus membrane elevation and implant placement. J Korean Assoc Oral Maxillofac Surg 2020 and implant placement ${ }^{40}$. Bone healing after sinus grafting is related to sinus width - the narrower is the width, the better is the prognosis ${ }^{41}$.

\section{Complications}

With regard to sinus membrane elevation surgery, some complications are inevitable even though prevention is the best method. Once complications occur, the clinician should acquaint themselves with the cause, explain the issue to the patient, and treat the complications accordingly. Cases of serious complications should be promptly referred to a related specialist ${ }^{42}$. During surgery, the most common complication is sinus membrane perforation, which could increase the risk of postoperative infection and failure of the graft and/or implant. Therefore, it is necessary to be aware of the various methods for closing perforations. After surgery, an infection is the most common complication, early diagnosis and treatment (antibiotics and incisional drainage) of which are very important for prevention of severe problems ${ }^{43,44}$.(Tables 2, 3)

To minimize complications such as bleeding and sinus membrane perforation, the normal anatomical structures and pathological findings should be identified and diagnosed before surgery. Cooperation with an otorhinolaryngologist should be considered in cases of asymptomatic maxillary sinus lesion, nasomeatal patency, chronic maxillary sinusitis, mucous retention cyst, and nasal septum deviation ${ }^{45}$. To prevent arterial bleeding, the clinician should evaluate the vertical resorption of alveolar bone and the position of the posterior superior alveolar artery ${ }^{46}$. Sinus lateral wall thickness is very different for each individual. If the wall thickness is too thin or thick, there is a high possibility of perforation of the sinus membrane during formation of the bony window ${ }^{47}$. Asymptomatic mucous retention cyst and antral pseudocyst are not a contraindication. However, mucoceles with extensive and destructive aspects are contraindication for sinus membrane elevation. Sinus elevation is often difficult in cases with

Table 3. Postoperative complications

1. Implant fixture sinus displacement

2. Hematoma

3. Wound dehiscence

4. Postoperative infection: maxillary sinusitis, graft material infection

5. Benign paroxysmal positional vertigo

6. Continuous neuropathic pain

7. Oroantral fistula

8. Infraorbital nerve damage

Young-Kyun Kim et al: Sinus membrane elevation and implant placement. J Korean Assoc Oral Maxillofac Surg 2020 
mucous retention cyst or pseudocyst, where aspiration with a 21-gauge needle could be effective for sinus elevation, bone grafting, and implant placement ${ }^{48}$. Sinus septum has been reported in $16 \%-58 \%$ of patients and could increase risk of membrane perforation ${ }^{49}$. Normal sinus membrane thickness is $0.3-0.8 \mathrm{~mm}$, and cilia cells remove various secretions and foreign substances formed in the maxillary sinus. If there is a lesion causing maxillary sinusitis or a history of sinus-related surgery, risk of postoperative complications such as maxillary sinusitis greatly increases because the cilia cells cannot function normally ${ }^{50}$. The most important factor to identify before surgery is maxillary ostium patency (osteomeatal patency), lack of which could cause postoperative maxillary sinusitis due to an issue with the maxillary sinus drainage system. In addition, risk of postoperative complications also increases in cases of nasal septum deviation and nasal mucosa inflammation or injury ${ }^{51}$.

\section{Clinical Outcomes}

\section{Implant protrusion into the maxillary sinus}

In an in vivo study of implant protrusion into the maxillary sinus, protrusion $\leq 2 \mathrm{~mm}$ was well covered with maxillary sinus mucosa, but protrusion $>3 \mathrm{~mm}$ was not completely healed by the mucosa and may have resulted in a secondary infection ${ }^{52}$. Ragucci et al. ${ }^{53}$ reported in a clinical study that protrusion $<4 \mathrm{~mm}$ resulted in a significantly lower incidence of maxillary sinusitis. Therefore, implant protrusion $<3 \mathrm{~mm}$ with sinus membrane perforation and loss of bone graft material should not be removed because of its ability to achieve osseointegration.

\section{Failure of sinus bone graft}

Anavi et al. ${ }^{54}$ reported the poor prognosis of implants in cases of previous sinus-related treatment and re-operation after complications from sinus bone graft surgery. Regarding treatment of chronic oroantral fistula reconstruction or reoperation with sinus bone grafting, $\mathrm{Kim}$ and $\mathrm{Kim}^{55}$ noted that sinus infection management should be considered with reconstruction of the sinus roof using a pedicled buccal fat pad and collagen membrane, oroantral fistula closure, and sinus bone graft using autogenous bone.

\section{Residual bone height and sinus width}

The crestal approach sinus lifting has fewer complications and higher success rates compared to lateral approach sinus lifting. This is attributed to the typical residual bone height greater than $5 \mathrm{~mm}$ when using the crestal approach ${ }^{56}$.

\section{Sinus membrane elevation and implant placement}

Simultaneous or delayed implant placement is determined by residual bone height. Therefore, direct comparison of prognosis is not appropriate between the two, and both have good prognoses if the timing of implant placement is determined based on all indications. The primary factor for implant success is primary stability ${ }^{57}$. Risk of implant failure greatly increases when implants are placed simultaneously with sinus bone graft and vertical ridge augmentation ${ }^{58}$.

\section{Risk factors of implant failure in the maxillary posterior region}

Sinus membrane elevation surgery is not directly related to implant failure. The main risk factors associated with implant failure are smoking, non-submerged implant, insufficient residual bone height, sinus membrane perforation, and postoperative maxillary sinusitis ${ }^{59,60}$.

\section{Summary}

1) Ideal bone graft materials have yet to be determined. However, a mixed bone graft (autogenous bone and other bone substitutes) has advantages in reducing the healing period and increasing bone density at the graft site over time compared with bone grafts using a certain material alone.

2) To prevent complications, the clinician should establish a careful preoperative examination and treatment plan based on the maxillary sinus structures. If lesions originating from the sinus are diagnosed before surgery, treatment should be performed with otolaryngology consultation.

3) Early detection and appropriate management are important to treat complications and prevent severe outcomes.

4) Several factors affect healing of maxillary sinus bone graft and prognosis of implants, the most important of which is residual bone height. 


\section{ORCID}

Young-Kyun Kim, https://orcid.org/0000-0002-7268-3870

Jeong-Kui Ku, https://orcid.org/0000-0003-1192-7066

\section{Author's Contributions}

Y.K.K. participated in the literature review and wrote the primary manuscript. J.K.K. participated in the literature review and wrote the final manuscript.

\section{Conflict of Interest}

No potential conflict of interest relevant to this article was reported.

\section{References}

1. Misch CE. Contemporary implant dentistry. 3rd ed. St. Louis: Elsevier; 2008:987-1043.

2. Timmenga NM, Raghoebar GM, van Weissenbruch R, Vissink A. Maxillary sinus floor elevation surgery. A clinical, radiographic and endoscopic evaluation. Clin Oral Implants Res 2003;14:322-8. https://doi.org/10.1034/j.1600-0501.2003.140310.x

3. Kim YW, Keum YS, Son HJ, Lee JY, Kim HC, Lee SC. Predictability of simultaneous implant placement with sinus floor elevation in the severely atrophic posterior maxillae; comparison of lateral and trans-crestal approaches. J Korean Dent Assoc 2010;48:205-17.

4. Toffler M. Site development in the posterior maxilla using osteocompression and apical alveolar displacement. Compend Contin Educ Dent 2001;22:775-80, 782, 784 passim; quiz 790.

5. Ferrigno N, Laureti M, Fanali S. Dental implants placement in conjunction with osteotome sinus floor elevation: a 12-year life-table analysis from a prospective study on 588 ITI implants. Clin Oral Implants Res 2006;17:194-205. https://doi.org/10.1111/j.16000501.2005.01192.X

6. Kim YK, Lee JY, Park JW, Kim SG, Oh JS. Sinus membrane elevation by the crestal approach using a novel drilling system. Implant Dent 2017;26:351-6. https://doi.org/10.1097/ ID.0000000000000570

7. Cassetta M, Ricci L, Iezzi G, Calasso S, Piattelli A, Perrotti V. Use of piezosurgery during maxillary sinus elevation: clinical results of 40 consecutive cases. Int J Periodontics Restorative Dent 2012;32:e182-8.

8. Sohn DS, Lee JS, An KM, Choi BJ. Piezoelectric internal sinus elevation (PISE) technique: a new method for internal sinus elevation. Implant Dent 2009;18:458-63. https://doi.org/10.1097/ ID.0b013e3181b8e17f

9. Bhandari S, Thomas R, Kumar T, Shah R, Mehta DS. Maxillary sinus augmentation using hydraulic pressure by lateral approach and simultaneous implant placement: clinicoradiographic study. Implant Dent 2019;28:514-9. https://doi.org/10.1097/ ID.0000000000000911

10. Kim YK, Kim SG. Sinus bone grafting technique using special reamers and microelevators. Implant Dent 2012;21:387-9. https:// doi.org/10.1097/ID.0b013e31826a56c3

11. Hatano N, Sennerby L, Lundgren S. Maxillary sinus augmentation using sinus membrane elevation and peripheral venous blood for implant-supported rehabilitation of the atrophic posterior maxilla: case series. Clin Implant Dent Relat Res 2007;9:150-5. https://doi. org $/ 10.1111 / j .1708-8208.2007 .00043 . x$

12. Han JD, Cho SH, Jang KW, Kim SG, Kim JH, Kim BJ, et al. Lateral approach for maxillary sinus membrane elevation without bone materials in maxillary mucous retention cyst with immediate or delayed implant rehabilitation: case reports. J Korean Assoc Oral Maxillofac Surg 2017;43:276-81. https://doi.org/10.5125/ jkaoms.2017.43.4.276

13. Steigmann M, Garg AK. A comparative study of bilateral sinus lifts performed with platelet-rich plasma alone versus alloplastic graft material reconstituted with blood. Implant Dent 2005;14:261-6. https://doi.org/10.1097/01.id.0000177412.84225.05

14. Gray CF, Redpath TW, Bainton R, Smith FW. Magnetic resonance imaging assessment of a sinus lift operation using reoxidised cellulose (Surgicel) as graft material. Clin Oral Implants Res 2001;12:526-30. https://doi.org/10.1034/j.1600-0501.2001.120514. $\mathrm{x}$

15. Parra M, Olate S, Cantín M. Clinical and biological analysis in graftless maxillary sinus lift. J Korean Assoc Oral Maxillofac Surg 2017;43:214-20. https://doi.org/10.5125/jkaoms.2017.43.4.214

16. Silva LD, de Lima VN, Faverani LP, de Mendonça MR, Okamoto R, Pellizzer EP. Maxillary sinus lift surgery-with or without graft material? A systematic review. Int J Oral Maxillofac Surg 2016;45:1570-6. https://doi.org/10.1016/j.ijom.2016.09.023

17. Fugazzotto PA, Pikos MA. Guided bone regeneration and sinus augmentation in the absence of autogenous bone grafting. Implant Dent 2001;10:158-61. https://doi.org/10.1097/00008505200107000-00002

18. Pignaton TB, Wenzel A, Ferreira CEA, Borges Martinelli C, Oliveira GJPL, Marcantonio E Jr, et al. Influence of residual bone height and sinus width on the outcome of maxillary sinus bone augmentation using anorganic bovine bone. Clin Oral Implants Res 2019;30:315-23. https://doi.org/10.1111/clr.13417

19. Schlegel KA, Schultze-Mosgau S, Wiltfang J, Neukam FW, Rupprecht S, Thorwarth M. Changes of mineralization of free autogenous bone grafts used for sinus floor elevation. Clin Oral Implants Res 2006;17:673-8. https://doi.org/10.1111/j.16000501.2006.01186.x

20. Kim YK, Hwang JW, Lee HJ, Yun PY. Use of the coronoid process as a donor site for sinus augmentation: a case report. Int J Oral Maxillofac Implants 2009;24:1149-52.

21. Artzi Z, Weinreb M, Carmeli G, Lev-Dor R, Dard M, Nemcovsky CE. Histomorphometric assessment of bone formation in sinus augmentation utilizing a combination of autogenous and hydroxyapatite/biphasic tricalcium phosphate graft materials: at 6 and 9 months in humans. Clin Oral Implants Res 2008;19:686-92. https:// doi.org/10.1111/j.1600-0501.2008.01539.x

22. Jang K, Lee JH, Oh SH, Ham BD, Chung SM, Lee JK, et al. Bone graft materials for current implant dentistry. J Dent Implant Res 2020;39:1-10.

23. Zhang W, Wang X, Wang S, Zhao J, Xu L, Zhu C, et al. The use of injectable sonication-induced silk hydrogel for $\operatorname{VEGF}(165)$ and BMP-2 delivery for elevation of the maxillary sinus floor. Biomaterials 2011;32:9415-24. https://doi.org/10.1016/ j.biomaterials.2011.08.047

24. Wu J, Li B, Lin X. Histological outcomes of sinus augmentation for dental implants with calcium phosphate or deproteinized bovine bone: a systematic review and meta-analysis. Int J Oral Maxillofac Surg 2016;45:1471-7. https://doi.org/10.1016/j.ijom.2016.04.020

25. Pereira RS, Gorla LF, Boos FBJD, Okamoto R, Garcia Júnior IR, Hochuli-Vieira E. Use of autogenous bone and beta-tricalcium phosphate in maxillary sinus lifting: histomorphometric study and immunohistochemical assessment of RUNX2 and VEGF. Int J Oral Maxillofac Surg 2017;46:503-10. https://doi.org/10.1016/ j.ijom.2017.01.002 
26. Pereira RS, Menezes JD, Bonardi JP, Griza GL, Okamoto R, Hochuli-Vieira E. Comparative study of volumetric changes and trabecular microarchitecture in human maxillary sinus bone augmentation with bioactive glass and autogenous bone graft: a prospective and randomized assessment. Int J Oral Maxillofac Surg 2018;47:665-71. https://doi.org/10.1016/j.ijom.2017.11.016

27. Bae JH, Kim YK, Kim SG, Yun PY, Kim JS. Sinus bone graft using new alloplastic bone graft material (Osteon)-II: clinical evaluation. Oral Surg Oral Med Oral Pathol Oral Radiol Endod 2010;109:e1420. https://doi.org/10.1016/j.tripleo.2009.10.047

28. Ku JK, Hong I, Lee BK, Yun PY, Lee JK. Dental alloplastic bone substitutes currently available in Korea. J Korean Assoc Oral Maxillofac Surg 2019;45:51-67. https://doi.org/10.5125/jkaoms.2019.45.2.51

29. Kim YK, Yun PY, Kim SG, Kim BS, Ong JL. Evaluation of sinus bone resorption and marginal bone loss after sinus bone grafting and implant placement. Oral Surg Oral Med Oral Pathol Oral Radiol Endod 2009;107:e21-8. https://doi.org/10.1016/ j.tripleo.2008.09.033

30. Kim YK, Yun PY, Kim SG, Lim SC. Analysis of the healing process in sinus bone grafting using various grafting materials. Oral Surg Oral Med Oral Pathol Oral Radiol Endod 2009;107:204-11. https://doi.org/10.1016/j.tripleo.2008.07.021

31. Starch-Jensen T, Aludden H, Hallman M, Dahlin C, Christensen $\mathrm{AE}$, Mordenfeld A. A systematic review and meta-analysis of longterm studies (five or more years) assessing maxillary sinus floor augmentation. Int J Oral Maxillofac Surg 2018;47:103-16. https:// doi.org/10.1016/j.ijom.2017.05.001

32. Gatti F, Gatti C, Tallarico M, Tommasato G, Meloni SM, Chiapasco M. Maxillary sinus membrane elevation using a special drilling system and hydraulic pressure: a 2-year prospective cohort study. Int J Periodontics Restorative Dent 2018;38:593-9. https:// doi.org/10.11607/prd.3403

33. Chackartchi T, Iezzi G, Goldstein M, Klinger A, Soskolne A, Piattelli A, et al. Sinus floor augmentation using large (1-2 mm) or small $(0.25-1 \mathrm{~mm})$ bovine bone mineral particles: a prospective, intra-individual controlled clinical, micro-computerized tomography and histomorphometric study. Clin Oral Implants Res 2011;22:47380. https://doi.org/10.1111/j.1600-0501.2010.02032.x

34. Suh DW, Lee DK, Lee SH. Clinical evaluation of delayed versus simultaneous implantation with sinus lifting. J Korean Assoc Oral Maxillofac Surg 2009;35:442-50.

35. Omori Y, Ricardo Silva E, Botticelli D, Apaza Alccayhuaman KA, Lang NP, Xavier SP. Reposition of the bone plate over the antrostomy in maxillary sinus augmentation: a histomorphometric study in rabbits. Clin Oral Implants Res 2018;29:821-34. https://doi. org $/ 10.1111 / \mathrm{clr} .13292$

36. Tanaka K, Iezzi G, Piattelli A, Ferri M, Mesa NF, Apaza Alccayhuaman KA, et al. Sinus floor elevation and antrostomy healing: a histomorphometric clinical study in humans. Implant Dent 2019;28:537-42. https://doi.org/10.1097/ID.0000000000000932

37. Venturelli A. A modified surgical protocol for placing implants in the maxillary tuberosity: clinical results at 36 months after loading with fixed partial dentures. Int J Oral Maxillofac Implants 1996;11:743-9.

38. Chiapasco M, Zaniboni M. Methods to treat the edentulous posterior maxilla: implants with sinus grafting. J Oral Maxillofac Surg 2009;67:867-71. https://doi.org/10.1016/j.joms.2008.11.023

39. Misch CE, Dietsh F. Endosteal implants and iliac crest grafts to restore severely resorbed totally edentulous maxillae--a retrospective study. J Oral Implantol 1994;20:100-10.

40. Jurisic M, Markovic A, Radulovic M, Brkovic BM, Sándor GK. Maxillary sinus floor augmentation: comparing osteotome with lateral window immediate and delayed implant placements. An interim report. Oral Surg Oral Med Oral Pathol Oral Radiol Endod 2008;106:820-7. https://doi.org/10.1016/j.tripleo.2008.04.025

41. Stacchi C, Lombardi T, Ottonelli R, Berton F, Perinetti G, Traini
T. New bone formation after transcrestal sinus floor elevation was influenced by sinus cavity dimensions: a prospective histologic and histomorphometric study. Clin Oral Implants Res 2018;29:465-79. https://doi.org/10.1111/clr.13144

42. On SW, Cho SW, Yang BE. A review of rare complications of maxillary sinus floor augmentation. J Korean Assoc Oral Maxillofac Surg 2019;45:351-6. https://doi.org/10.5125/jkaoms.2019.45.6.351

43. Kim SG, Baik SM. Diagnosis and treatment of maxillary sinusitis after implant placement. Implant Dent 2010;19:115-21. https://doi. org/10.1097/ID.0b013e3181d43a76

44. Stacchi C, Andolsek F, Berton F, Perinetti G, Navarra CO, Di Lenarda R. Intraoperative complications during sinus floor elevation with lateral approach: a systematic review. Int J Oral Maxillofac Implants 2017;32:e107-18. https://doi.org/10.11607/jomi.4884

45. Hsiao YJ, Yang J, Resnik RR, Suzuki JB. Prevalence of maxillary sinus pathology based on cone-beam computed tomography evaluation of multiethnicity dental school population. Implant Dent 2019;28:356-66. https://doi.org/10.1097/ID.0000000000000902

46. Varela-Centelles P, Loira-Gago M, Seoane-Romero JM, Takkouche B, Monteiro L, Seoane J. Detection of the posterior superior alveolar artery in the lateral sinus wall using computed tomography/cone beam computed tomography: a prevalence meta-analysis study and systematic review. Int J Oral Maxillofac Surg 2015;44:1405-10. https://doi.org/10.1016/j.ijom.2015.07.001

47. Zijderveld SA, van den Bergh JP, Schulten EA, ten Bruggenkate CM. Anatomical and surgical findings and complications in 100 consecutive maxillary sinus floor elevation procedures. $\mathrm{J}$ Oral Maxillofac Surg 2008;66:1426-38. https://doi.org/10.1016/ j.joms.2008.01.027

48. Kim SB, Yun PY, Kim YK. Clinical evaluation of sinus bone graft in patients with mucous retention cyst. Maxillofac Plast Reconstr Surg 2016;38:35. https://doi.org/10.1186/s40902-016-0081-1

49. Ulm CW, Solar P, Krennmair G, Matejka M, Watzek G. Incidence and suggested surgical management of septa in sinus-lift procedures. Int J Oral Maxillofac Implants 1995; 10:462-5.

50. Benninger MS, Sebek BA, Levine HL. Mucosal regeneration of the maxillary sinus after surgery. Otolaryngol Head Neck Surg 1989;101:33-7. https://doi.org/10.1177/019459988910100107

51. Kang DW, Yun PY, Choi YH, Kim YK. Sinus bone graft and simultaneous vertical ridge augmentation: case series study. Maxillofac Plast Reconstr Surg 2019;41:36. https://doi.org/10.1186/s40902019-0221-5

52. Zhong W, Chen B, Liang X, Ma G. Experimental study on penetration of dental implants into the maxillary sinus in different depths. J Appl Oral Sci 2013;21:560-6. https://doi.org/10.1590/1679775720130078

53. Ragucci GM, Elnayef B, Suárez-López Del Amo F, Wang HL, Hernández-Alfaro F, Gargallo-Albiol J. Influence of exposing dental implants into the sinus cavity on survival and complications rate: a systematic review. Int J Implant Dent 2019;5:6. https://doi. org/10.1186/s40729-019-0157-7

54. Anavi Y, Allon DM, Avishai G, Calderon S. Complications of maxillary sinus augmentations in a selective series of patients. Oral Surg Oral Med Oral Pathol Oral Radiol Endod 2008;106:34-8. https://doi.org/10.1016/j.tripleo.2007.09.021

55. Kim YK, Kim SG. A retrospective analysis of the retreatment of failed sinus bone grafts. Implant Dent 2016;25:450-4. https://doi. org/10.1097/ID.0000000000000420

56. Kim SM, Park JW, Suh JY, Sohn DS, Lee JM. Bone-added osteotome technique versus lateral approach for sinus floor elevation: a comparative radiographic study. Implant Dent 2011;20:465-70. https://doi.org/10.1097/ID.0b013e31823545b2

57. Becktor JP, Isaksson S, Sennerby L. Endosseous implants and bone augmentation in the partially dentate maxilla: an analysis of $17 \mathrm{pa}-$ tients with a follow-up of 29 to 101 months. Int J Oral Maxillofac Implants 2007;22:603-8.

58. Yamamichi N, Itose T, Neiva R, Wang HL. Long-term evaluation 
of implant survival in augmented sinuses: a case series. Int J Periodontics Restorative Dent 2008;28:163-9.

59. Park WB, Kang KL, Han JY. Factors influencing long-term survival rates of implants placed simultaneously with lateral maxillary sinus floor augmentation: a 6- to 20-year retrospective study. Clin Oral Implants Res 2019;30:977-88. https://doi.org/10.1111/ clr. 13505

60. Kim YK, Hwang JY, Yun PY. Relationship between prognosis of dental implants and maxillary sinusitis associated with the sinus elevation procedure. Int J Oral Maxillofac Implants 2013;28:17883. https://doi.org/10.11607/jomi.2739

How to cite this article: $\mathrm{Kim}$ YK, Ku JK. Sinus membrane elevation and implant placement. J Korean Assoc Oral Maxillofac Surg 2020;46:292-298. https://doi.org/10.5125/jkaoms.2020.46.4.292 